\title{
Correction to: Avoiding Help Avoidance: Using Interface Design Changes to Promote Unsolicited Hint Usage in an Intelligent Tutor
}

\author{
Mehak Maniktala $^{1}$ (D) $\cdot$ Christa Cody $^{1} \cdot$ Tiffany Barnes $^{1} \cdot$ Min Chi $^{1}$ \\ Published online: 2 December 2020 \\ (C) International Artificial Intelligence in Education Society 2020
}

\section{Correction to: Int J Artif Intell Educ \\ https://doi.org/10.1007/s40593-020-00213-3}

The corrected Fig. 6 is provided below. While generating higher quality figures for publication, an error was made in this figure where the numbers for the Unproductive Low Effort - Low HJR (red) and Productive - High Effort - High HJR (green) were interchanged. The graph below shows that majority of the Assertions-Low group students are in the Productive - High Effort - High HJR cluster.

The online version of the original article can be found at https://doi.org/10.1007/s40593-020-00213-3

Mehak Maniktala mmanikt@ncsu.edu

1 Department of Computer Science, North Carolina State University, Raleigh, NC, USA 


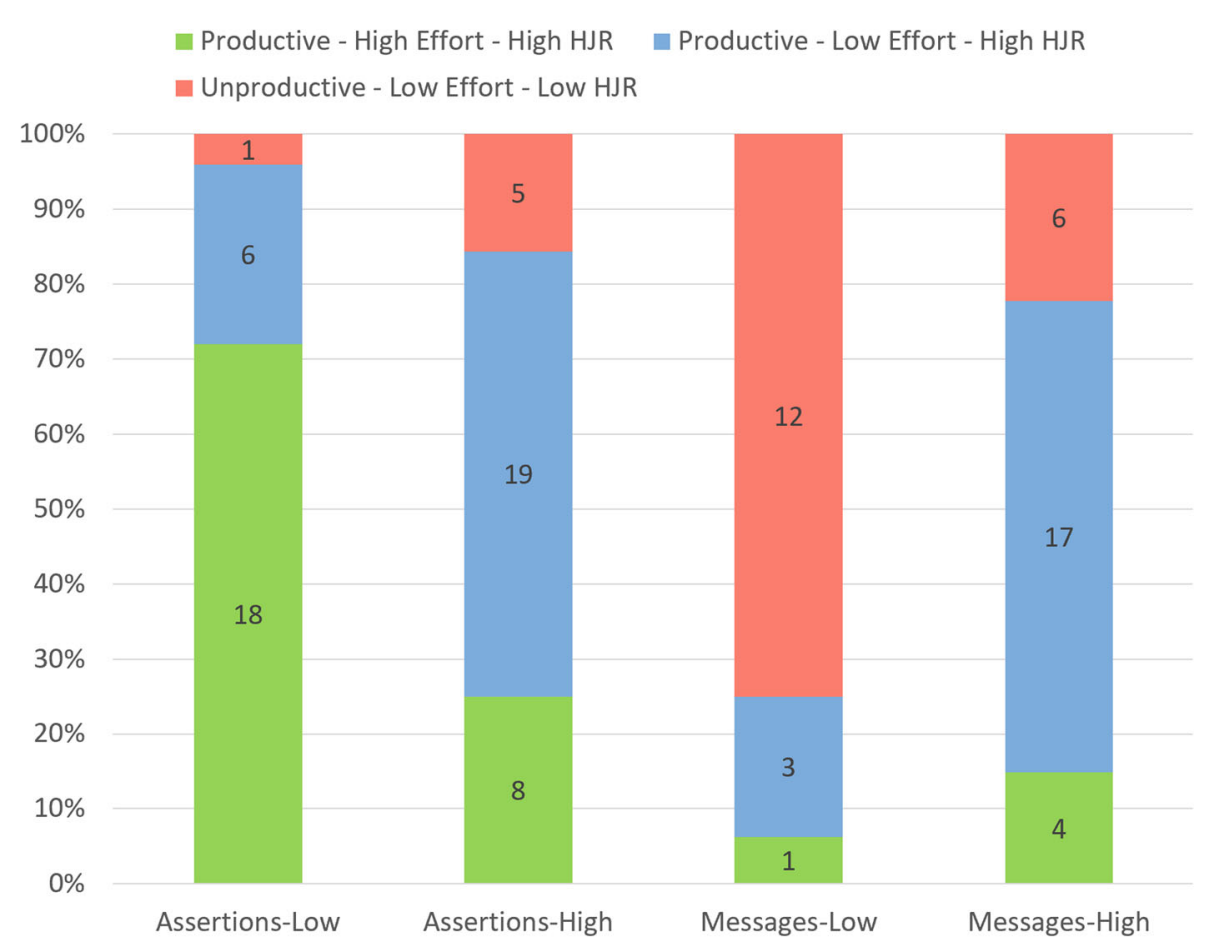

Fig. 6 Profile of the three Clusters based on the Condition and Prior Proficiency

Publisher's Note Springer Nature remains neutral with regard to jurisdictional claims in published maps and institutional affiliations. 